\title{
Correlates of Partner Violence Among Female Street-Based Sex Workers: Substance Abuse, History of Childhood Abuse, and HIV Risks
}

\author{
NABILA EL-BASSEL, D.S.W., ${ }^{1}$ SUSAN S. WITTE, Ph.D., ${ }^{1}$ TAKESHI WADA, M.Phil., ${ }^{1}$ \\ LOUISA GILBERT, M.A., ${ }^{1}$ and JOYCE WALLACE, Ph.D. ${ }^{2}$
}

\begin{abstract}
This study examines the prevalence of physical and sexual abuse by intimate and commercial sexual partners among street-based sex workers and explores correlates of partner abuse by commercial partners using the following factors: sociodemographics, substance abuse, sexual behavior, and physical and sexual childhood abuse. One hundred thirteen street sex workers were recruited from December 1996 through May 1997 while receiving services from the Foundations for Research on Sexually Transmitted Diseases (FROST'D), a nonprofit organization based in New York City. Partner abuse is a common occurrence among street sex workers. Two of three street prostitutes have experienced lifetime physical or sexual abuse by either an intimate or commercial partner. In addition, one of eight reported physical and sexual abuse by both intimate and commercial partners during her lifetime. Women who were homeless in the last year, those who reported exchanging for drugs and money as their main source of income, used injection drugs in the past year and had sex in crack houses, and who were human immunodeficiency virus (HIV)-positive were more likely to be report combined physical and sexual abuse. Understanding the relationship between partner violence, victim's substance abuse, and HIV-risk behavior is important for the development of public policies and treatment and prevention strategies to address the constellation of problems that drug-using female street sex workers face.
\end{abstract}

\section{INTRODUCTION}

W OMEN WHO EXCHANGE SEX for money or drugs in street-based settings confront an array of intersecting social problems that include: poverty, homelessness, incarceration, substance abuse (particularly crack/cocaine), human immunodeficiency virus/acquired immune deficiency syndrome (HIV / AIDS), physical and sexual partner violence, and history of childhood abuse. ${ }^{1-6}$ Studies showed that the majority of the female street-based sex workers are more likely to be homeless and poor and that sex trading is their major source of income. ${ }^{7,8}$

Sexual and physical abuse and rape are also prevalent among prostitutes. ${ }^{4,7,8}$ In a study of 130 prostitutes, $82 \%$ reported that they had been physically assaulted, $83 \%$ had been threatened with a weapon, and $68 \%$ had been raped

${ }^{1}$ Social Intervention Group, Columbia University, ${ }^{2}$ Foundations for Research on Sexually Transmitted Diseases, New York, New York. 
while working as a prostitute. ${ }^{9}$ In another study conducted among 1,104 women in three urban communities where illicit drug use was common, $13.7 \%$ of the women reported being raped in the year before the interview. ${ }^{8}$ Rape survivors in this study were more likely to report exchanging sex for money or drugs in the previous 30 days.

Drug-involved women have been shown to be at an increased risk of partner abuse. The association between drug use and partner violence is explained in the literature by several pathways. A drug-using lifestyle may lead to partner violence because the routine activities and behaviors associated with using illicit drugs, including: involvement in buying, selling, and obtaining drugs; visiting shooting galleries and crack houses; conflicts around splitting and sharing drugs with main and casual partners; being forced to supply drugs for main partners through sex trading; stealing, or "hustling," which increase her risk of experiencing violent traumas of all types, including rape and physical assault by drug dealers and sex partners. ${ }^{10-13}$

Second, the physiological effects and cultural expectancies of different drugs on women may increase their likelihood of experiencing partner violence. Researchers have suggested that crack/cocaine use may increase a woman's verbal aggression against her partner, which may in turn evoke a negative response, including more severe physical or sexual aggression in retaliation. ${ }^{14}$ In addition, previous studies have suggested that paranoia, impaired judgment, or distorted interpretation of social cues, which occur as a result of drug use, may also lead to aggressive responses. ${ }^{15-17}$

Third, women who are dependent on drugs and acquire the stigma of being "crackheads," "potheads," or "drug addicts" may be at a higher risk of violence from their partners because they are perceived as violating cultural norms of acceptable female behavior. ${ }^{14}$ Violence that is directed toward drug-using women might be explained by gender role expectations. A women who uses drugs may be perceived as engaging in inappropriate gender roles that increase her risk of abuse because her partner perceives her actions as improper. A drunken man may be perceived as funny, whereas a drunken woman is often viewed as obnoxious or unfeminine. ${ }^{18}$ Some women have a tendency to become verbally aggressive when they drink, violating gender role norms. ${ }^{19} \mathrm{Be}-$ cause women on crack often sell sex for drugs, this activity may result in further conflicts about appropriate female behavior.

Fourth, another line of inquiry suggests that partner violence leads to substance abuse. Burnam et al. ${ }^{20}$ found increased rates of substance abuse after physical assault and sexual abuse in adulthood among a probability sample of women and men.

Finally, other studies have found that partner violence and substance abuse are reciprocal in nature. In their recent study, Kilpatrick et al. ${ }^{21}$ found a cyclical relationship in which substance abuse increases the risk for future physical and sexual assault and physical and sexual assault increases the risk of subsequent substance abuse.

The higher rates of partner violence among commercial sex workers may be also linked to conflicts over condom use. One study of 165 primarily low-income, African American women found a significant association between recent incidence of physical partner violence and a lack of condom use. ${ }^{22}$ Another study of 141 women who used urban health clinics found that physical partner violence was associated with unprotected sex in the previous month. ${ }^{23}$ In a more recent study using qualitative data on 64 battered women taking methadone, a significant number indicated that past experience and fear of violence prevented them from asking their partner to use a condom. ${ }^{24}$ A woman may risk serious harm from her partner(s) if she informs him that she is HIV positive. Indeed, there have been cases of women being shot, injured, and abandoned as a result of partner notification. ${ }^{25}$

Sexually abused women may suffer from anal, genital, and nongenital trauma ${ }^{26-28}$ that may increase their risk of HIV transmission. ${ }^{29}$ Women often experience anal penetration during rape $\mathrm{e}^{27,30}$ and receptive anal intercourse is the most efficient sexual mode of HIV transmission. ${ }^{29}$ Condoms are rarely used in nonconsensual intercourse. ${ }^{4,8,24}$ Studies have shown that up to one-third of female rape survivors may have ulcerative and nonulcerative bacterial 
sexually transmitted diseases (STDs) that increase the risk of HIV transmission. ${ }^{26-28,31}$

This study examines the prevalence of physical and sexual partner violence by intimate and commercial sexual partners among 105 female street-based sex workers. It also describes the relationship between sexual and physical abuse from commercial sexual partners and the following factors:

1. Sociodemographics (age, ethnicity, marital status, having a regular intimate relationship, homelessness, incarceration, and if commercial sex was the main source of income).

2. History of childhood abuse (physical and sexual abuse).

3. Substance abuse (use of alcohol, marijuana, crack/cocaine, heroin, injection drug use, methadone treatment, and visiting "crack houses").

4. Sexual risk behavior (condom use with both intimate and commercial partners, number of sex exchanges, self-reported HIV serostatus).

Finally, using stepwise multiple logistic regression, the study explores correlates of abuse by commercial partners using the above-described factors as independent variables. We did not explore correlates of abuse by intimate partners because few women had a regular sexual partner at the time of the study. It is important to note that we did not intend to examine pathways among the above risk factors, but only how they are associated with commercial partner abuse.

This study focuses on a topic that has been little studied among street sex workers. Despite the small sample size, this study should extend the knowledge base on the relationship between violence by commercial partners, drug use, HIV-risk behaviors, and history of victimization among street sex workers.

\section{METHODS}

One hundred thirteen street-based sex workers were recruited from December 1996 through May 1997 while receiving services from the Foundations for Research on Sexually Transmitted Diseases (FROST'D), a nonprofit organization based in New York City. A mobile van outreach unit was used to both recruit participants and conduct the research (i.e., identify locations, conduct interviews, etc.). Within the general outreach program, the unit visits and identifies sex work "strolls" (locations) throughout New York City and is available 1 day per week at each location. Service includes education, food, clothing, assistance in obtaining a social security card and in applying for government entitlements, and access to drug treatment programs. The majority of participants in this study were from East Harlem and the Bronx. After being informed of the project's purpose, each women completed a 30minute face-to-face interview. More than $90 \%$ of the women whom we recruited for the study agreed to participate. The interview was conducted for 110 women by trained interviews who were not FROST'D staff. The interview covered demographic characteristics, drug use history, history of victimization, sexual risk behavior, and experiences of partner abuse. In order to ensure anonymity, researchers collected no identifying information. Four interviews were incomplete and two interviews were missing data on dependent variables, leaving a total of 106 interviews from which data were analyzed.

\section{Dependent variable}

The dependent variable consists of physical and sexual abuse by commercial sexual partners during last year. We asked the following questions: "When exchanging sex for money or drugs during the last year, how many times were you physically abused?" and "When exchanging sex for money or drugs during the last year, how many times were you forced to have sex when you did not want to, or sexually abused or raped?" For each question the respondents chose one of the following answers: never, once, twice, 3-5 times, 6-10 times, 11-20 times, and more than 20 times. Then, we dichotomized their answers into "never" and "once or more." A combined partner abuse variable was constructed. If a respondent answered "once or more" to either one or both 
variables, "once or more" was assigned to the combined abuse variable. If she answered "never" to both, "never" was assigned to the combined variable.

\section{Correlate variables}

Correlates were selected based on earlier research, as discussed in the introduction. They include sociodemographic, drug abuse, sexual HIV-risk behavior, and childhood abuse variables.

Sociodemographic variables include continuous variables (age, years of education), categorical variables (ethnicity [African American, Latina, other]), and marital status (single, married, separated/divorced/widowed), and dichotomous variables (having an intimate sexual partner, living with children, currently homeless, incarcerated during the past year, commercial sex as the main source of income). Drug use variables are dichotomous (current use of alcohol, marijuana, intravenous heroin, nasal heroin, and crack/cocaine, currently being in methadone treatment), and categorical (visiting a "crack house" or "shooting gallery" during the last year [never visited, visited but never had sex there, visited and sometimes had sex there]). Sexual risk variables include continuous variables (the average number of sex exchanges per week, the number of commercial partners, and the number of years engaged in sex work), categorical variable (accepting money or drugs in exchange for sex without using a condom [never offered, offered but never accepted the offer, offered and sometimes accepted the offer]), and dichotomous variables (always used a male condom with regular partner, always used a male condom with commercial partners, refused to have sex with intimate partner because he did not agree to use a condom, and refused to have sex with commercial partner because he did not agree to use a condom, HIV serostatus). Childhood abuse variables are dichotomized (physical and sexual abuse under 18 years old).

\section{Data analysis}

Both univariate and multivariate analyses were conducted to explore correlates of physical and sexual abuse by commercial partners.
In addition, univariate and bivariate association between the correlates and the dependent variable were examined by using both $t$ tests for continuous variables and $\chi^{2}$ tests for categorical and dichotomous variables.

Finally, stepwise multiple logistic regression was used to build models that best fit the observed data. The stepwise procedure, although not acceptable for theory testing purposes, is a useful tool for exploratory research, in which "the phenomenon is so new or so little studied that existing "theory" amounts to little more than empirically unsupported hunches about explanations for the phenomenon." 32

Backward elimination rather than forward inclusion stepwise method was used in the analysis. A correlate may appear to have a statistically significant effect only when another predictor is controlled. Stepwise procedure with forward inclusion may exclude a significant predictor from the final model if another predictor is also excluded. With backward elimination, there is less risk of failing to find such a significant predictor because all the predictors are included in the initial model.

The statistical significance criterion for elimination was set at $10 \%$. The usual $5 \%$ criterion for statistical significance may be too strict and often ends up eliminating important predictors from the model. A strict criterion also tends to exclude those "control variables" that would make other predictors statistically significant if they were included in the model. This results in an increase in type I error (finding a significant relationship that is not actually significant) and a decrease in type II error (not finding a significant relationship when one exists). The exploratory nature of this research called for placing greater emphasis on finding prospective correlates rather than the elimination of suspicious ones.

The following correlates were entered into the initial model: age, years of education, ethnicity, marital status, having an intimate partner, living with children, being homeless, being incarcerated, commercial sex as main source of income, the current use of alcohol, marijuana, intravenous heroin, nasal heroin, and crack/cocaine, being in methadone treatment, visiting a crack house or shooting gallery, the average number of sex exchanges 
per week, HIV serostatus, and childhood physical and sexual abuse. Sexual risk variables related to intimate partners were not used because of missing cases.

This method requires that the cases contain information on all correlates included in the initial model. Due to this constraint, four cases with missing data in one of the predictors were excluded from the analysis. The multivariate analysis includes 102 cases.

\section{Diagnostics of multicollinearity}

Extremely high correlations among the correlates in the logistic regression models can seriously distort the estimates of the variances (and, as a result, the standard errors) of the coefficients. ${ }^{33}$ To detect this multicolinearity problem, we looked at the following statistics: simple correlation and tolerance.

First, we inspected the correlation matrix of the correlates. None of the correlates included in the initial model exhibited extremely high correlation among each other, which would have required us to take corrective measures (some suggest the criteria of high correlation as about 0.8 or $0.9^{34,35}$ ).

Second, after the logistic regression analysis, we examined the tolerance statistics because we might not have detected serious collinearity problems solely by looking at simple correlations. Due to the unavailability of collinearitydetective measures for the logistic regression models, we ran linear regressions for the same set of dependent variable and predictors in the logistic regression models to see the tolerance. This is a defensible strategy because our concern is with the relationship among the pre- dictors, while the functional form of the model for the dependent variable is irrelevant to the estimation of collinearity. ${ }^{32}$

\section{RESULTS}

\section{Partner abuse}

Table 1 describes the prevalence of physical or sexual abuse by commercial and intimate sex partners in the respondent's lifetime and in the past year.

More than $50 \%$ of the women experienced physical or sexual abuse during her lifetime from commercial partners, whereas $73 \%$ of the women with intimate partners experienced physical or sexual abuse from intimate partners. Although physical abuse by commercial and intimate partners in the last year were similar, more women reported sexual violence from commercial partners than intimate partners in the last year $(22.0 \%$ vs. $4.0 \%)$.

\section{Sociodemographic background and partner violence by commercial sex partners}

Table 2 describes the sociodemographic backgrounds of participants and their association with partner violence by commercial partners. The average age of the sex workers was 35.3 years $(\mathrm{SD}=8.0)$ and the average educational level was 11.5 years $(\mathrm{SD}=2.2$ ). Approximately two-thirds were single and African American. Forty-two percent of respondents reported having a regular intimate partner and $64 \%$ acknowledged that commercial sex was their main source of income.

Table 1. Sex Workers' Experience of Partner Violence by Intimate and Commercial Partners

\begin{tabular}{|c|c|c|}
\hline & Lifetime & In the past year \\
\hline & $\%(\mathrm{n})$ & $\%(\mathrm{n})$ \\
\hline \multicolumn{3}{|l|}{ Abuse by an intimate partner $\mathrm{N}=45$} \\
\hline Physical abuse & $57.8(26)$ & $20.0(9)$ \\
\hline Sexual abuse & $42.2(19)$ & $8.9(4)$ \\
\hline Physical and sexual abuse combined & $73.3(33)$ & $22.2(10)$ \\
\hline \multicolumn{3}{|l|}{ Abuse by commercial partners $\mathrm{N}=106$} \\
\hline Physical abuse & $45.3(48)$ & $23.6(25)$ \\
\hline Sexual abuse & $34.9(37)$ & $20.8(22)$ \\
\hline Physical and sexual abuse combined & $50.0(53)$ & $32.1(34)$ \\
\hline
\end{tabular}


Table 2. Associations Between Abuse of Sex Workers by Commercial

PARTNERS AND SOCIODEMOGRAPHIC BACKGROUND $(N=106)$

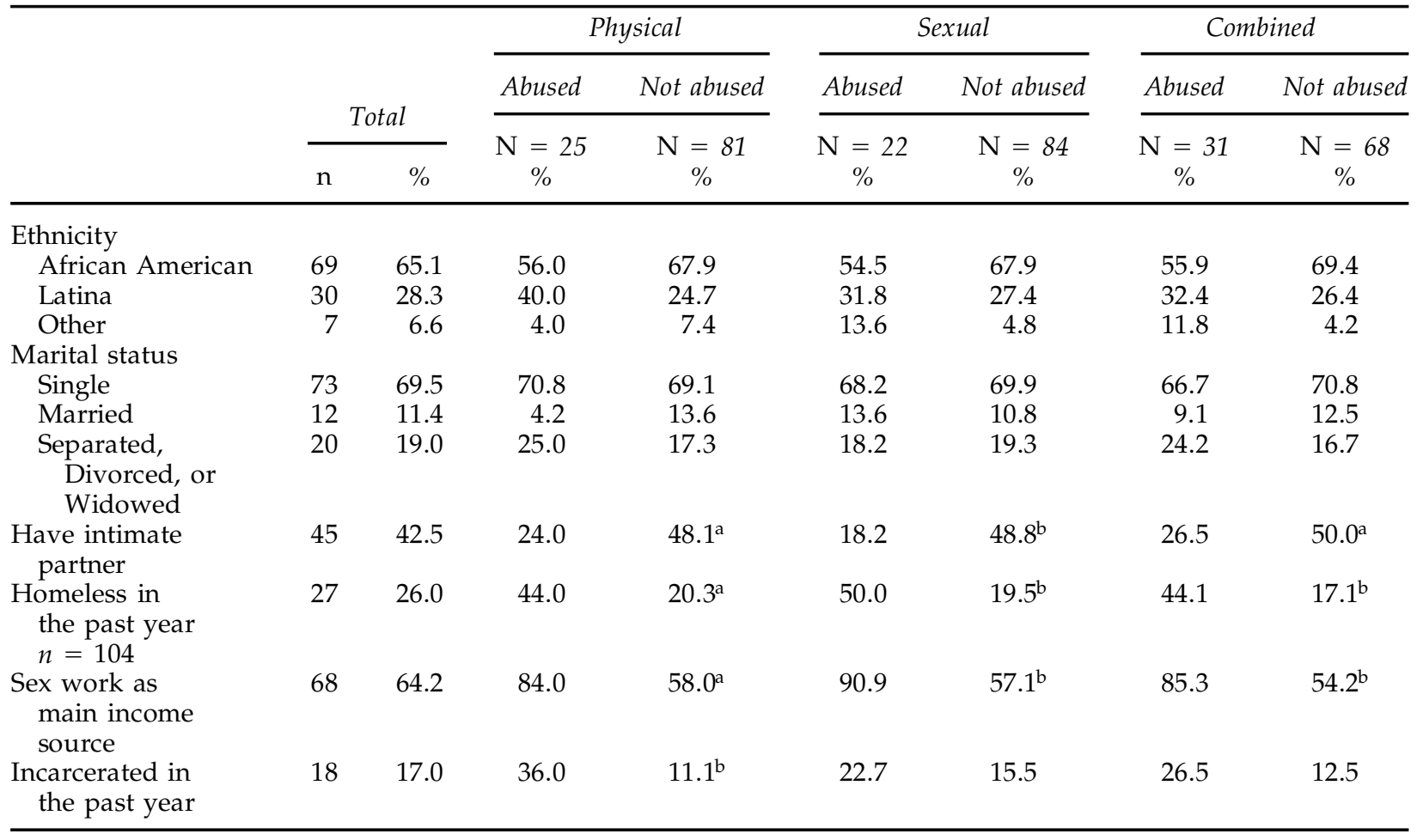

${ }^{\mathrm{a}} p<0.05 ;{ }^{\mathrm{b}} p<0.01$.

Age, years of education, ethnicity, marital status, and living with children were not associated with partner violence variables. Respondents with a regular intimate partner were less likely than those without an intimate partner to be physically and sexually abused by commercial sex partners $(p<0.033$ and $p<$
0.010 respectively). Being homeless significantly increased the risk of being abused by commercial partners. Respondents who had been incarcerated during the past year were more likely to be physically abused by commercial partners than those who had not $(p<$ $0.004)$. If sex work was the major source of in-

Table 3. Associations Between Abuse of Sex Worker by Commercial Partners and Childhood Abuse Variables $(N=106)$

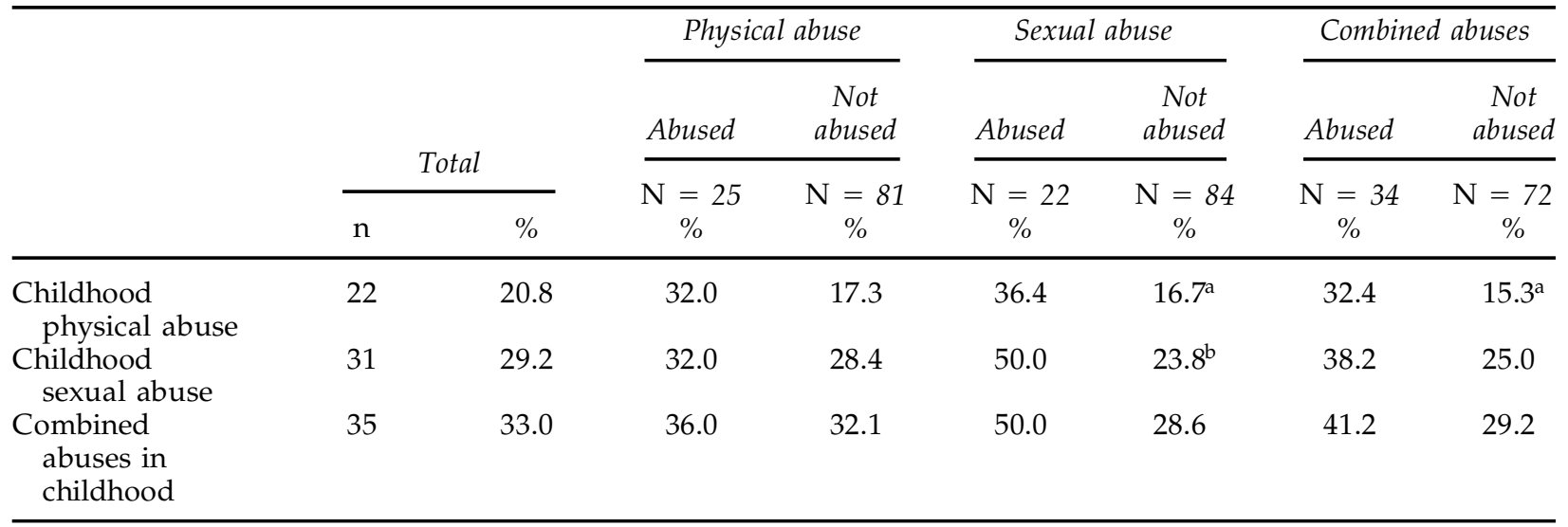

$$
{ }^{\mathrm{a}} p<0.05 ;{ }^{\mathrm{b}} p<0.01
$$


come, the woman was more likely to be physically $(p<0.018)$ and sexually $(p<0.003)$ abused by commercial partners than her counterparts.

\section{Childhood abuse}

Table 3 describes the experience of childhood abuse and the association with three partner abuse variables. Thirty-three percent of participants reported that they were abused when they were younger than 18 years old: $22 \%$ reported childhood physical abuse and 31\% sexual abuse. Although childhood physical abuse and childhood sexual abuse were both significantly associated with sexual abuse by commercial partners, current physical abuse was not.

\section{Drug use}

Table 4 describes drug use variables and their association with three partner abuse variables. Half of the respondents reported current alcohol use. The majority indicated current use of crack/cocaine, slightly less than half had visited a crack house during the past year, and of those less, less than $21 \%$ exchanged sex there.

Injection drug use was positively associated with all three abuse variables $(p<0.001$ for all abuse variables). Abused women were more likely than nonabused women to be current crack/cocaine users (94\% vs. 79\%, $p<0.050$ ). Visiting a crack house was significantly related to having been either physically or sexually abused by a commercial partner $(p<0.023)$.

Sexual risk behavior and partner violence by commercial sex partners

Table 5 describes sexual risk behaviors and their association with the three abuse variables. Thirty-six percent of respondents who had an intimate partner reported always using male condoms with him, while 56\% reported always using condoms with commercial sexual partners. Respondents exchanged sex for money or drugs an average of 24 times per week during the past year. Fourteen percent of the respondents were HIV positive.

Physical and sexual abuse by intimate and commercial partners were associated with number of sex exchanges and HIV status at the bivariate level. The more often the woman exchanged sex for money or drugs, the more likely she was to be physically abused by commercial partners $(p<0.013)$. While physically abused participants exchanged sex 38 times per week on average during the past year, nonabused counterparts exchanged sex 20

Table 4. Associations Between Abuse of Sex Workers by Commercial Partners and Current Drug Use $(N=106)$

\begin{tabular}{|c|c|c|c|c|c|c|c|c|}
\hline & & & \multicolumn{2}{|c|}{ Physical } & \multicolumn{2}{|c|}{ Sexual } & \multicolumn{2}{|c|}{ Combined } \\
\hline & \multicolumn{2}{|c|}{ Total } & Abused & $\begin{array}{c}\text { Not } \\
\text { abused }\end{array}$ & Abused & $\begin{array}{c}\text { Not } \\
\text { abused }\end{array}$ & Abused & $\begin{array}{c}\text { Not } \\
\text { abused }\end{array}$ \\
\hline & $\mathrm{n}$ & $\%$ & $\begin{array}{c}\mathrm{N}=25 \\
\%\end{array}$ & $\begin{array}{c}\mathrm{N}=81 \\
\%\end{array}$ & $\begin{array}{c}\mathrm{N}=22 \\
\%\end{array}$ & $\begin{array}{c}\mathrm{N}=84 \\
\%\end{array}$ & $\begin{array}{c}\mathrm{N}=34 \\
\%\end{array}$ & $\begin{array}{c}\mathrm{N}=72 \\
\%\end{array}$ \\
\hline Alcohol use & 53 & 50.0 & 36.0 & 54.3 & 31.8 & 54.8 & 38.2 & 55.6 \\
\hline Marijuana use & 20 & 18.9 & 8.0 & 22.2 & 9.1 & 21.4 & 8.8 & 23.6 \\
\hline Intravenous heroin use & 22 & 20.8 & 48.0 & $12.3^{\mathrm{b}}$ & 50.0 & $13.1^{\mathrm{b}}$ & 44.1 & $9.7^{\mathrm{b}}$ \\
\hline Nasal heroin use & 10 & 9.4 & 8.0 & 9.9 & 18.2 & 7.1 & 11.8 & 8.3 \\
\hline Methadone treatment & 12 & 11.3 & 8.0 & 12.3 & 4.5 & 13.1 & 8.8 & 12.5 \\
\hline Cocaine/crack use & 89 & 84.0 & 96.0 & 80.2 & 95.5 & 81.0 & 94.1 & $79.2^{\mathrm{a}}$ \\
\hline \multicolumn{9}{|l|}{ Crack house $n=105$} \\
\hline Never visited & 54 & 51.4 & 40.0 & 55.0 & 31.8 & 56.6 & 35.3 & $59.2^{\mathrm{a}}$ \\
\hline $\begin{array}{l}\text { Visited, never } \\
\text { with sex }\end{array}$ & 29 & 27.6 & 28.0 & 27.5 & 40.9 & 24.1 & 29.4 & 26.8 \\
\hline $\begin{array}{l}\text { Visited, traded sex } \\
\text { for money or drugs }\end{array}$ & 22 & 21.0 & 32.0 & 17.5 & 27.3 & 19.3 & 35.3 & 14.1 \\
\hline
\end{tabular}

${ }^{\mathrm{a}} p<0.05 ;{ }^{\mathrm{b}} p<0.01$. 
Table 5. Associations Between Abuse of Sex Workers by Commercial

Partners and Sexual Risk Behavior Variables $(n=106)$

\begin{tabular}{|c|c|c|c|c|c|c|c|c|}
\hline & & & \multicolumn{2}{|c|}{ Physical abuse } & \multicolumn{2}{|c|}{ Sexual abuse } & \multicolumn{2}{|c|}{ Abuse combined } \\
\hline & \multirow{2}{*}{\multicolumn{2}{|c|}{ Total }} & Abused & $\begin{array}{l}\text { Not } \\
\text { abused }\end{array}$ & Abused & $\begin{array}{l}\text { Not } \\
\text { abused }\end{array}$ & Abused & $\begin{array}{l}\text { Not } \\
\text { abused }\end{array}$ \\
\hline & & & $\mathrm{N}=25$ & $\mathrm{~N}=81$ & $\mathrm{~N}=22$ & $\mathrm{~N}=84$ & $\mathrm{~N}=34$ & $\mathrm{~N}=72$ \\
\hline & $\mathrm{n}$ & $\%$ & $\%$ & $\%$ & $\%$ & $\%$ & $\%$ & $\%$ \\
\hline $\begin{array}{l}\text { Always used condoms } \\
\text { with intimate partner } \\
n=45\end{array}$ & 16 & 35.6 & $\begin{array}{c}16.7 \\
(n=6)\end{array}$ & $\begin{array}{c}38.5 \\
(n=39)\end{array}$ & $\begin{array}{c}50.0 \\
(n=4)\end{array}$ & $\begin{array}{c}34.1 \\
(n=41)\end{array}$ & $\begin{array}{c}33.3 \\
(n=9)\end{array}$ & $\begin{array}{c}36.1 \\
(n=36)\end{array}$ \\
\hline $\begin{array}{l}\text { Always used condoms } \\
\text { with customers }\end{array}$ & 59 & 55.7 & 60.0 & 54.3 & 59.1 & 54.8 & 58.8 & 54.2 \\
\hline $\begin{array}{l}\text { Number of sex } \\
\text { exchanges }\end{array}$ & $\begin{array}{c}\mathrm{m}=24.1 \\
(\mathrm{SD}=31.8)\end{array}$ & & $\begin{array}{l}37.8 \\
(27.3)\end{array}$ & $\begin{array}{l}19.9^{\mathrm{a}} \\
(32.0)\end{array}$ & $\begin{array}{l}30.1 \\
(17.4)\end{array}$ & $\begin{array}{l}22.6 \\
(34.5)\end{array}$ & $\begin{array}{l}33.1 \\
(24.9)\end{array}$ & $\begin{array}{l}19.9^{\mathrm{a}} \\
(33.9)\end{array}$ \\
\hline HIV status & & & & & & & & \\
\hline Positive & 15 & 14.2 & 32.0 & $8.6^{\mathrm{b}}$ & 18.2 & 13.1 & 26.5 & $8.3^{\mathrm{a}}$ \\
\hline
\end{tabular}

${ }^{\mathrm{a}} p<0.05 ;{ }^{\mathrm{b}} p<0.01$.

times per week. Thirty-two percent of the physically abused women were infected with HIV. In contrast, only $8.6 \%$ of nonabused respondents were seropositive. When physical and sexual abuses were combined, $27 \%$ of abused women were HIV positive, while $8 \%$ of their counterparts were HIV positive $(p<$ 0.012).

\section{Multivariate analyses}

Table 6 shows the result of stepwise multiple logistic regression on the combined abuse (physical and sexual) by commercial partners. The model's $\chi^{2}$ was $41.98(d f=5, p<0.000)$. Participants who were homeless and whose main income came from sex work were more likely to report physical and sexual abuse by commercial partners. Those who injected heroin were much more likely than noninjectors to be abused by commercial partners. Respondents who had sex in crack houses were more likely to be abused than those who had not visited crack houses. HIV-positive sex workers were more likely than their seronegative counterparts to be abused.

Table 6. Predictors of Physical and Sexual Partner Violence by Commercial Partners: the Result of the Stepwise Logistic Regression Analysis with Backward Elimination $(n=102)$

\begin{tabular}{|c|c|c|c|}
\hline & Odds ratio & Confidence interval & $\mathrm{p}$ \\
\hline Being homeless & 3.27 & $(0.99,10.83)$ & 0.052 \\
\hline Sex work as main income source & 3.59 & $(0.91,14.21)$ & 0.068 \\
\hline HIV positive & 3.86 & $(0.91,16.41)$ & 0.068 \\
\hline Intravenous heroin use & 9.81 & $(2.67,36.00)$ & 0.001 \\
\hline \multicolumn{4}{|l|}{ Visited crack houses } \\
\hline Never with sex & 2.89 & $(0.79,10.61)$ & \\
\hline Traded sex for money or drugs & 8.70 & $(2.11,35.78)$ & 0.003 \\
\hline$-2 \mathrm{LL}$ & 86.44 & & \\
\hline Model $\chi^{2}$ & 41.98 & & \\
\hline$d f$ & 5 & & \\
\hline Significance & $<0.0001$ & & \\
\hline
\end{tabular}

The variables in the initial model: age, years of education, ethnicity, marital status, having an intimate partner, living with children, being homeless during the past year, being incarcerated during the past year, sex work as main income, the use of alcohol, marijuana, intravenous heroin, nasal heroin, and crack/cocaine, being in methadone treatment, visiting crack house or shooting gallery, the number of sex exchanges per week, HIV status, and combined childhood physical and sexual abuses. 


\section{DISCUSSION}

Partner abuse is a common occurrence among street-based sex workers. Street-based sex workers may tolerate sexual abuse by commercial partners because they perceive it is "part of the job." This is especially true for those who are homeless or rely on prostitution as their primary source of income.

The study's findings in the univariate analysis showed that respondents who have a regular intimate partner tend to report fewer episodes of sexual and physical abuse by commercial partners. We speculate that the intimate partner may protect her from exploitation by commercial partners, or the intimate partner may be her pimp. This issue needs to be further explored.

The findings also support what other studies have shown; street-based sex workers live in poverty, tend to experience homelessness and incarceration, and rely on prostitution as their major source of income. These macro-social factors increase a woman's vulnerability and may also increase the likelihood that she may use drugs to cope. Moreover, the bivariate analysis, findings suggest that women who experienced childhood physical and sexual abuse were more likely to report sexual abuse by a commercial partner as an adult. As a result of earlier trauma, women may continue to be mired in a vicious cycle of partner abuse as well as drug abuse. These findings support other studies on similar traumas. ${ }^{36-39}$

Using bivariate analysis, women who injected drugs and used crack/cocaine were more likely to report physical and sexual abuse by commercial partners than those who did not use these types of drugs. Little is understood about the link between a woman's drug use and partner violence. It is plausible that the altered state produced by the substance abuse directly leads to violence. However, we posit that social and contextual factors mediate violence among substance abusers.

The findings suggest that visiting crack houses is related to being physically or sexually abused by commercial partners. Findings in the univariate analysis showed that two sexual risk variables, number of sex exchanges and being HIV positive, were related to physical, but not sexual, abuse by commercial partners. Condom use was not related to sexual or physical violence by commercial partners. Condom use overall, however, remained low with both intimate and commercial partners.

The multivariate findings on the combined physical and sexual abuse variable suggests that women who were homeless in the last year, those who reported sex work as their main source of income, used injection drugs in the last year, had sex in crack houses, and who were HIV positive were more likely to be at risk of combined physical and sexual abuse.

\section{Research implications}

Several limitations of this study bear mention. First, given the study's small and nonrandom sample, the findings are not necessarily generalizable to all female sex workers in street-based settings. Second, standardized tests were not used to measure partner violence and substance abuse. In addition, sexual abuse was defined to include the range from sexual coercion to rape. Third, we did not include macro-level variables such as exposure to community violence, access to sources of help, or unemployment rates in the community, which may confound findings. Moreover, the crosssectional design precluded the study of temporal relationships among substance abuse and partner violence and HIV-risk behavior. The relationship between partner violence and illicit drug use by the victim remains unclear and underresearched. Longitudinal population-based studies, as well as those among female streetbased sex workers, will be required in order to understand the temporal relationships among the three phenomena.

The social, contextual, cultural, relationship, and gender roles and inequalities associated with drug use and partner violence are also understudied. In order to understand these factors and the mechanisms whereby they mediate partner violence, future research must also include qualitative methodologies such as focus groups, in-depth narrative interviews, ethnographic research and life histories. For example, through in-depth interviews with women, researchers would be able to elicit detailed phenomenological and contextual narra- 
tives of precisely how partner abuse episodes evolve, and to identify the cultural, gender roles and social factors and the mechanisms by which they mediate the two phenomena.

\section{Implications for HIV interventions}

Our study demonstrates that sex workers are especially vulnerable to physical and sexual abuse by both intimate and commercial partners. Public health interventions for street prostitutes are likely to fail unless they are integrated with basic services such as housing, public assistance, education, viable employment opportunities, and prevention of drug abuse and partner violence.

Understanding the relationship between partner violence, the victim's substance abuse, and HIV-risk behavior is important for the development of public policies and treatment and prevention strategies to address the constellation of problems that drug-using female streetbased sex workers face. More coherent public policies and treatment and prevention strategies may also reduce future victimization and interrupt the severity of drug abuse.

In the last several years, there has been an increase in the level of awareness of domestic violence among staff in drug treatment programs, community organizations, and outreach programs for sex workers. However, such violence is rarely addressed in the assessment protocols and treatment approaches by the staff in these settings.

Given the co-occurrence of substance abuse, partner violence and HIV risks among female street-based sex workers, assessment and intervention on partner violence are crucial. They must be an integral part of the assessment protocol in drug treatment or other programs, such as FROST'D (from which the study participants were recruited), designed to assist sex workers.

In order to prevent partner violence and reduce its prevalence among drug abusing sex workers, it is also essential that prevention efforts include education for these women about their heightened risk of partner violence and strategies on how they might increase their safety. In addition, these efforts should include behavioral skills training such as problem solving, coping, and help-seeking skills. These skills may also sensitize female commercial sex workers to be more attentive to the risks of partner violence, and provide them with alternative coping mechanisms and safety planning for risky situations. Moreover, prevention efforts should consider macro-intervention at the community level. In order to address social norms towards violence against street-based sex workers, prevention efforts should also extend to all sex workers through outreach programs, drug treatment programs, emergency departments, homeless shelters, soup kitchens, etc.

\section{REFERENCES}

1. Zierler S, Fiengold D, Velentgas P, Kantrowitz-Gordon I, Mayer K. Adult survivors of childhood sexual abuse and subsequent risk of HIV infection. Am J Public Health 1991;81:572-575.

2. Miller BA, Downs WR, Testa M. Interrelationships between victimization experiences and women's alcohol use. J Studies Alcohol 1993;11:109-117.

3. El-Bassel N, Gilbert L, Schilling R, Ivanoff A, Borne, D. Correlates of crack abuse among drug-using incarcerated women: Psychological trauma, social support, and coping behavior. Am J Drug Alcohol Abuse et al. 1996;22:41-56.

4. El-Bassel N, Schilling R, Irwin K, et al. Sex trading and psychological distress among women recruited from the streets of Harlem. Am J Public Health 1997;87:66-70.

5. Witte S, El-Bassel N, Wada T, Gray O, Wallace J. Acceptability of female condom use among women exchanging street sex in New York City. Int J STD AIDS 1999;10:162-168.

6. Witte S, Wada T, El-Bassel N, Gilbert L, Wallace J. Predictors of female condom use among women exchangin street sex. Sex Transm Dis 2000;27:93.

7. El-Bassel N, Simoni J, Cooper D, Schilling R. Psychological distress and sex trading among women on methadone. Psychol Addict Behav (in press).

8. Irwin K, Edlin B, Wong L, et al. Urban rape survivors: Characteristics and prevalence of human immunodeficiency virus and other sexually transmitted infections. Obstet Gynecol 1995;85:330-336.

9. Teets J. The incidence and experience of rape among chemically dependent women. J Psychoactive Drugs 1997;29:331-336.

10. Fullilove MT, Lown A, Fullilove RE. Crack "hos and skeezers: Traumatic experiences of women crack users. J Sex Res 1992;29:275-287.

11. Cottler L, Compton W, Mager D, Spitznagel E, Janca A. Posttraumatic stress disorder among substance users from the general population. Am J Psychiatry 1992;149:664-670. 
12. Fullilove $M$, Fullilove $R$, Smith $M$, et al. Violence, trauma, and post-traumatic stress disorder among women drug users. J Trauma Stress 1993;6:533-543.

13. Inciardi J, Lockwood D, Pottiger A. Women and Crack-Cocaine. New York: Macmillan, 1993.

14. Miller BA. The Interrelationships Between Alcohol and Drugs and Family Violence. National Institute of Drug Abuse Monograph 103. 1990, pp 177-207.

15. Brody S. Introduction: Exploring the Substance Abuse-Violence Connection. National Institute of Drug Abuse Research Monograph 103.

16. Miller NS, Gold M, Mahler JC. Violent behaviors associated with cocaine use: Possible pharmacological mechanisms. Int J Addictions 1991;26:1077-1088.

17. Spunt BJ, Goldstein PJ, Bellucci PA, Miller T. Race/ethnicity and gender differences in the drugsviolence relationship. J Psychoactive Drugs 1990;22: 293-303.

18. Kagle J. Women who drink: Changing images, changing realities. J Soc Wk Ed 1987;3:21-28.

19. Sandmaier M. The invisible alcoholics: Women and alcohol abuse in America. J Abnormal Psychol 1980; 41:1229-1230.

20. Burnam M, Stein J, Golding J, et al. Sexual assault and mental disorders in a community population. J Consult Clinical Psychol 1988;56:843-850.

21. Kilpatrick D, Acierno R, Resnick H, Saunders B, Best C. A 2-year longitudinal analysis of the relationships between violent assault and substance use in women. J Consult Clinical Psychol 1997;65:834-837.

22. Wingood G, Hunter-Gamble D, DiClemente R. A pilot study of sexual communcation and negotiation among young African American women: Implications for HIV prevention. J Black Psychol 1993;19: 190-203.

23. Morrill A, Ickovics J. Surviving abuse and HIV risk: How women's experience of abuse shapes their heterosexual risk for HIV [Tu.D. 134]. XI International Conference on AIDS. Vancouver, Canada, July 1996.

24. El-Bassel N, Gilbert L, Raja V, Frye V. Fear and violence: Raising the HIV stakes. AIDS Educ Prev 2000;12(2):154-170.

25. North R, Rothenberg K. Partner notification and the threat of domestic violence against women with HIV infection. N Engl J Med 1993;329:1194-1196.

26. Jenny C, Hooton T, Bowers A, et al. Sexually transmitted diseases in victims of rape. $\mathrm{N}$ Engl J Med 1990;322:713-716.

27. Satin A, Hemsell D, Stone I, Theriot S, Wendel G. Sex- ual assault in pregnancy. Am J Obstet Gynecol 1991;77:710-714.

28. Satin A, Ramin S, Paicurich J, Millman S, Wendel G. The prevalence of sexual assault: A survey of 2404 puerperal women. Am J Obstet Gynecol 1992;167: 973-975.

29. Padian N, Marquis L, Francis D, et al. Male to female transmission of human immunodeficiency virus. JAMA 1987;258:788-790.

30. Glaser J, Schachter J, Benes S, Cummings M, Frances C, McCormack W. Sexually transmitted diseases in postpubertal female rape victims. J Infect Dis 1991; 164:726-730.

31. Davies A, Clay J. Prevalence of sexually transmitted disease infection in women alleging rape. Sex Transm Dis 1992;19:298-300.

32. Menard S. Applied Logistic Regression Analysis. Thousand Oaks, CA: Sage, 1995.

33. Gujarati D. Basic Econometrics. New York: McGraw Hill, 1988.

34. Kennedy P. A Guide to Econometrics. 3rd ed. Cambridge, MA: The MIT Press, 1992:180.

35. Bohrstedt G, Knoke D. Statistics for Social Data Analysis. 3rd ed. Itasca, IL: F.E. Peacock Publishers, 1994:300.

36. Wingood G, DiClemente R. The effects of an abusive primary partner on the condom use and sexual negotiation practices of African-American women. Am J Public Health 1997;87:1016-1018.

37. Zierler S, Witbeck B, Mayer K. Sexual violence against women living with or at risk for HIV infection. Am J Prev Med 1996;12:304-310.

38. Wyatt GE, Guthrie D, Notgrass CM. Differential effects of women's child sexual abuse and subsequent revictimization. J Consult Clin Psychol 1992;60:167-173.

39. Wyatt G. The sexual abuse of Afro-American and white-American women in childhood. Child Abuse Neglect 1985;9:507-519.

Address reprint requests to: Nabila El-Bassel Director of SIG Associate Professor Columbia University 622 West 113th Street New York, NY 10025

E-mail: ne5@columbia.edu 